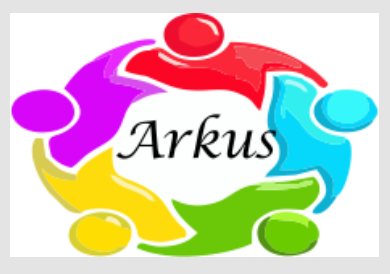

\title{
ARKUS
}

Journal Homepage:

https://hmpublisher.com/index.php/arkus

\section{Phototherapy in Dermatology}

\section{Inda Astri Aryani ${ }^{*}$, Maria Mayfinna Gozali ${ }^{1}$, Indri Widyasari ${ }^{1}$}

${ }^{1}$ Department of Dermatology and Venereology, Faculty of Medicine, Sriwijaya University / Dr. Mohammad Hoesin General Hospital, Palembang, Indonesia

\section{A R T I C L E I N F O \\ Keywords: \\ Phototherapy \\ Dermatology \\ UV \\ Corresponding author: \\ Inda Astri Aryani \\ E-mail address: \\ inda_astri@gmail.com}

All authors have reviewed and approved the final version of the manuscript.

https://doi.org/10.37275/arkus.v1i1.119

\begin{abstract}
A B S T R A C T
Phototherapy is a therapeutic procedure in dermatology. Phototherapy uses certain ultraviolet wavelengths classified into 3 types,broadband UVB (BBUVB), narrowband UVB (NBUVB), and psoralen UVA (PUVA). The most widely used is NBUVB for treating psoriasis, atopic dermatitis and vitiligo. The mechanism of action of phototherapy is to reduce epidermal proliferation, suppress the immune system, reduce the inflammatory process, and induce repigmentation. Before starting phototherapy, the dose adjustment depends on skin type and minimal erythema dose (MED). Frequency of use is recommended based on the severity of the disease, continuously administered needed. Besides of this therapeutic effect, some contraindications and side effects that need to be considered in the use of phototherapy such as drug interactions, photoallergic and risk of skin malignancy.
\end{abstract}

\section{Introduction}

Based on wavelength, ultraviolet (UV) light consists of 3 groups, namely ultraviolet A (UVA) 320$400 \mathrm{~nm}$, ultraviolet B (UVB) 290- $320 \mathrm{~nm}$, and ultraviolet C (UVC) 200-290 $\mathrm{nm}$. When it reaches the skin's surface, ultraviolet light can undergo several processes, namely reflected, scattered, entered into the layers of the skin, and absorbed. UV light absorbed by the chromophore can produce photobiological effects. ${ }^{1}$ The absorption of UV light depends on the wavelength and is influenced by the structure of the chromophore. The chromophore is a light-absorbing molecule. The chromophore in the epidermis and dermis comes from endogenous and exogenous. Known endogenous chromophores include DNA, melanin, hemoglobin, water, urocanic acid, amino acids, flavins, 7-dehydrocholesterol (a precursor of vitamin D), porphyrins. Exogenous chromophores include photosensitizing drugs (fluoroquinolones, azathioprine, 8-methoxypsoralen) and sunscreens. The most clinically important endogenous chromophore is DNA because it absorbs UVB and some UVA. The effects of UV rays affect human life, including the skin. The effects of UV rays on the skin include acute effects and chronic effects. The acute effects required are in the form of vitamin D synthesis, while the unwanted chronic effects include skin malignancy. 1-4 For hundreds of years, natural sunlight has been known to provide many benefits in several skin disorders, and some of the ultraviolet radiation produced by the sun is used in 
phototherapy. Phototherapy can be a therapeutic modality in various skin disorders, such as psoriasis, atopic dermatitis, vitiligo, solar urticaria, pruritus, pityriasis rosea, alopecia areata, acne vulgaris. 5 Phototherapy is classified into 3 types, namely broadband UVB (BBUVB), narrowband UVB ( NBUVB), as well as psoralen and UVA (PUVA). There are various types of phototherapy equipment. 1) Types of fluorescent lamps 2) Types of metal halide lamps. Based on their form and use, examples of UVB phototherapy include: whole-body stand-up fluorescents, metal halide stand-up units, lie-down fluorescent units, hand and foot units, and area units. and currently the most widely used NBUVB.6 In general, the mechanism of action of phototherapy on the skin is to reduce skin inflammation, but it is temporary. The cost of phototherapy is relatively affordable with great benefits for cases of severe skin disorders so that it can be a treatment option, especially for psoriasis, vitiligo, and severe atopic dermatitis. ${ }^{7}$

\section{Phototherapy in psoriasis}

Psoriasis is a chronic inflammatory skin disease, based on genetics accompanied by environmental triggers in the form of trauma, infection and the use of certain drugs. Psoriasis can be treated with various regimen options, one of which is phototherapy. 8 Psoriasis is responsive to phototherapy. This therapy has become the standard treatment for psoriasis, especially for moderate-to-severe psoriasis. Phototherapy is a form of dermatosis treatment using light of high-intensity UV wavelengths. First-line phototherapy in the treatment of psoriasis uses UVB phototherapy. The wavelength of UVB phototherapy radiation is $280-320 \mathrm{~nm}$ and is one of the therapies with the highest satisfaction rate compared to other therapeutic modalities. ${ }^{8}$ The mechanism of action of phototherapy is selective depletion of $\mathrm{T}$ cells, generally in the epidermis. The mechanism of depletion is similar to the apoptotic process and is accompanied by a shift in the immune response of Th1 cells to the immune response of Th2 cells in skin lesions, as well as reducing the number and function of antigen-presenting Langerhans cells. UVB phototherapy causes several pathological changes in psoriasis lesions, including decreased keratinocyte proliferation. ${ }^{9}$ The key role of keratinocyte apoptosis in the therapeutic effect of UVB in psoriasis was recently investigated by Weatherhead, showing that keratinocyte apoptosis plays a significant role in the healing of psoriasis plaques. The number of $\mathrm{T}$ lymphocytes in the epidermis and dermis was also shown to be decreased, possibly due to UVB-induced apoptosis. Although the decrease in epidermal T cells correlated well with clinical improvement, the number of dermal cells was not demonstrated. Epidermal and dermal cell counts were significantly more reduced by NB-UVB than by BB-UVB. T lymphocytes in vitro were 10 times more sensitive to UVB cytotoxic effects than keratinocytes, which explains the thinning of the epidermis on UVB phototherapy.9,10 According to the American Academy of Dermatology, Phototherapy is given to psoriasis patients $2-3 \mathrm{x} /$ week for effective results. However, in some cases it can be given 5 times a week. ${ }^{11}$ The indications for UVB psoriasis phototherapy include: moderate-severe psoriasis with BSA > 10\%, patients avoid oral drugs, lesions quickly disappear when exposed to sunlight, thin itnic c lesions, mother pregnant or breastfeeding, and young age.

\section{Phototherapy in vitiligo}

Vitiligo is a disease due to the depigmentation process of the skin, caused by itch and non-itch factors that interact with the loss or survival of melanocyte function and is an autoimmune event. ${ }^{12}$ The main therapy for vitiligo for decades is phototherapy. Since 1948, PUVA has been widely used and has produced promising results. Although PUVA is effective, PUVA has the characteristics of 
phototoxic effects, nausea, the risk of skin malignancy, and cannot be applied to pediatric patients or pregnant women due to the use of psoralen. Since 1997, NBUVB has been reported to be effective in the treatment of vitiligo with minimal side effects, so that until now NBUVB is the standard therapy for generalized vitiligo. However, PUVA is still used for vitiligo cases with special conditions that require deeper UVA penetration. ${ }^{13}$ The goal of phototherapy in vitiligo is skin repigmentation. It takes a minimum of 1 year to achieve maximum response. In some studies, the optimal frequency of therapy is $2-3 x /$ week for NBUVB in vitiligo. Repigmentation is determined by the number of therapy sessions. The dose given depends on the location of the lesion and the Fitzpatrick type of skin. ${ }^{13}$

\section{Phototherapy in atopic dermatitis}

Atopic dermatitis is skin inflammation in the form of chronic residive dermatitis, accompanied by itching, andcertain body parts, especially the face in infants (infantile phase) and the flexural parts of the extremities. (in the pediatric phase). ${ }^{14}$ In itch dermatitis, phototherapy has an effect on the immune system by reducing the number of $\mathrm{T}$ cells in the skin that play a role in producing red, itchy, and painful skin so that it can reduce symptoms, the surface area of the body affected, and reduce the need for use. itnic corticosteroids. ${ }^{15}$ Phototherapy is indicated in adult and pediatric patients with moderate to severe itnic dermatitis who does not respond to conventional therapy with itch steroids and emollients and has a reduced quality of life. However, in some patients who are itnic c to UV or have photoallergic abnormalities, this therapy cannot be performed.15 The type of phototherapy given for itch dermatitis that requires long-term itnic steroids is NBUVB, but PUVA is more effective in more severe disease that does not respond against NBUVB. ${ }^{15}$

\section{Conclusion}

UVA and UVB rays have a therapeutic effect in reducing epidermal proliferation, suppressing the immune system and reducing the inflammatory process. Phototherapy is indicated for moderatesevere psoriasis, moderate-severe atopic dermatitis unresponsive to conventional therapy, and vitiligo. Consideration of the choice of phototherapy should consider the indications, contraindications and side effects that can occur. Phototherapy shows good efficacy, but it is very necessary for patient compliance in undergoing therapy on a regular basis so that the therapeutic effect is achieved.

\section{References}

1. Young AR. Photobiology. In: Griffiths CE, Barker J, Blelker T, Chalmers R, creamer D, editors. Rook's Textbook of Dermatology 9th. Inggris; Wiley Blackwell. 2010; 257-70.

2. Runger TM. Ultraviolet Light. In: Bolognia JL, Jorizzo JL, Schaffer JV, editors. Dermatology 3 rd. Philadelphia: Elsevier. 2012; 1455-65.

3. Young AR, Claveau J, Rossi AB. Ultraviolet radiation and the skin: Photobiology and sunscreen photoprotection. J Am Acad Dermatol. 2017; 76: S100-9.

4. Morison WL, Fitzpatrick TB. Phototherapy and photochemotherapy of skin disease. Edisi ke-2. New York: Raven Press, 1991; 10-26.

5. Morison WL. Management of Psoriasis Vulgaris. In: Morison WL. Phototherapy and Photochemotherapy of Skin Disease. 3rd ed. USA: Taylor and Francis Group; 2005; 45-155.

6. Lim HW, Sliparcha N, Amadi U, Menter A, Voorhees AS, Lebwohl M. Phototerapy 
in dermatology: A call for action. J Am Acad Dermatol.2015; 72(6): 1078-80.

7. Gudjonsson JE, Elder JT. Psoriasis. In: Wolff K, Goldsmith LA, Katz SI, Gilchrest BA, Paller AS, Leff el DJ, editors. Fitzpatrick's dermatology in general medicine. 8th ed. New York: McGraw-Hill Companies Inc. 2012; 197-231.

8. Racz E, Prens E. Phototherapy and Photochemotherapy for Psoriasis. Dermatol Clin. 2015; 33: 79-89.

9. Reich A, Medrek K. Effects of Narrow Band UVB (311 nm) Irradiation on Epidermal Cells. Int J Mol Sci. 2013; 14: 8456-66.

10. American Academy of Dermatology. Psoriasis treatment: phototherapy. Cited on 29 August 2019. Available at https://www.aad.org/public/diseases/s caly-skin/psoriasis/diagnosis-and -treatment-of-psoriasis/phototherapy

11. Kandaswamy S, Akhtar N, Shenoi SD. Phototherapy in Vitiligo: Assessing the compliance, response and patient's perception abost disease and treatment. Indian J Dermatol. 2013; 53(4): 325-31.

12. Bae JM, Jung HM, Hong BY, Lee JH, Choi WJ, Lee JH, et al. Phototherapy for vitiligo A systematic review and metaanalysis. JAMA Dermatol. 2017; 3: 1-9.

13. Boediarja. Dermatitis Atopik. In: Menaldi SL, Bramono K, Indriatmi W. Ilmu Penyakit Kulit dan Kelamin. Edisi ke-7. Jakarta: Badan Penerbit FKUI. 2017: 167-83.

14. National eczema association. Phototherapy to treat eczema. Cited on 29 August 2019. Available at https://nationaleczema.org/eczema/tre atment/phototherapy/

15. Matz H. Phototherapy for Psoriasis: what to choose and how to use: facts and controversies. J Clindermatol. 2010; 28: 73-80. 